\title{
Effects of Shen'an granules on Wnt signaling pathway in mouse models of diabetic nephropathy
}

\author{
XIN-RONG ZOU, XIAO-QIN WANG, YING-LIN HU and HUI-LAN ZHOU \\ Department of Nephrology, Hubei Provincial Hospital of Traditional Chinese Medicine, Wuhan, Hubei 430061, P.R. China
}

Received March 8, 2016; Accepted July 26, 2016

DOI: $10.3892 /$ etm. 2016.3800

\begin{abstract}
The effect of Shen'an granules on the Wnt signaling pathway in renal tissues of mouse models of streptozotocin (STZ)-induced diabetic nephropathy was investigated in the present study. A total of $62 \mathrm{BALB} / \mathrm{c}$ mice were randomly divided into the normal control (A group), model (B group), losartan (C group), low-dose Shen'an granules (D group), and high-dose Shen'an granules (E group) groups. The mouse model of diabetic nephropathy was established by a single intraperitoneal injection of STZ $(150 \mathrm{mg} / \mathrm{kg})$. The animals were treated with drugs for 8 weeks, and blood creatinine, blood urea nitrogen, triglycerides (TG), and total cholesterol (CHOL) were measured prior to and after treatment. PAS staining was performed for observation of glomerular microstructure by light microscope, and western blot analysis was performed to detect Wnt1 protein and $\beta$-catenin protein. The results indicated that the quantification of 24-h microalbuminuria, and levels of blood creatinine, urea nitrogen, TG, and CHOL were significantly lower in the high- and low-dose Shen'an granules groups than those in the model group $(\mathrm{p}<0.05)$. The expression levels of Wnt1 protein and $\beta$-catenin protein in the high- and low-dose Shen'an granules groups were significantly lower than those in the model group $(\mathrm{p}<0.05)$. In conclusion, proteinuria, renal dysfunction, and dyslipidemias are closely associated with the abnormal activation of the Wnt signaling pathway in the mouse model of diabetic nephropathy. The mechanism by which Shen'an granules regulate proteinuria, renal function, and blood lipids may be associated with inhibition of the abnormally activated Wnt signaling pathway.
\end{abstract}

\section{Introduction}

The activation or inactivation of the Wnt signaling pathway is orderly regulated, and is important in the regulation of physiological processes, including cell differentiation, proliferation and apoptosis (1). The development, morphology, and

Correspondence to: Dr Xin-Rong Zou, Department of Nephrology, Hubei Provincial Hospital of Traditional Chinese Medicine, 4 Huanyuan Mountain, Wuhan, Hubei 430061, P.R. China

E-mail: xin_rongzou1@163.com

Key words: Shen'an granules, diabetic nephropathy, Wnt1, $\beta$-catenin functional maintenance of the kidney are dependent on the normal 'open' and timely 'close' of the Wnt signaling pathway.

Inappropriate activation of the Wnt signaling pathway may lead to a series of disorders, including developmental malformations, carcinogenesis, tumorigenesis, osteoporosis, Parkinson's disease and aging (1). Previous findings have shown that sustained activation of the Wnt signaling pathway is commonly associated with proteinuria and glomerulosclerosis in diabetic nephropathy $(2,3)$.

In the present study, we investigated the potential mechanism of the Wnt signaling pathway affecting diabetic nephropathy and the intervening effect of Shen'an granules on the pathway.

\section{Animals and methods}

Mice. A total of 62 male 8-week-old BALB/c mice $(n=62)$ (purchased from Hubei Province Animal Research Center, Hubei, China) of SPF grade, weighing 18-22 g, were selected for this study. The mice were housed in a temperature-controlled room $\left(21 \pm 2^{\circ} \mathrm{C}\right)$ on a 12:12-h light/dark cycle (lights on at 06:00). The mice had free access to water and food. The experimental protocol was approved by the Animal Care and Use Committee of Huazhong University of Science and Technology.

Drugs and reagents. Shen'an granule suspension (epimedium, astragalus and rhubarb, ratio $2: 2: 1$ ) was prepared by the Hubei Provincial Hospital of Traditional Chinese Medicine (Hubei, China). Losartan potassium tablets $(50 \mathrm{mg} /$ tablet $)$ were provided by Hangzhou MSD Pharmaceutical Co., Ltd. (Hangzhou, China), and $1 \mathrm{mg} / \mathrm{ml}$ suspension was made using distilled water. Streptozotocin (STZ) was purchased from Sigma (St. Louis, MO, USA). Horseradish peroxidase (HRP)-labeled goat anti-rabbit polyclonal antibody and HRP-labeled goat anti-rabbit polyclonal antibody were purchased from KPL, Inc. (Gaithersburg, MD, USA).

Generation of the mouse model of diabetic nephropathy. After 10 days of normal feeding, the animals were fasted for $12 \mathrm{~h}$ prior to the intraperitoneal injection of STZ $(150 \mathrm{mg} / \mathrm{kg})$ dissolved in citrate buffer ( $\mathrm{pH} 4.5)$. The injection was administered once in all the groups of mice with the exception of the normal control group. After $72 \mathrm{~h}$, blood samples were collected from the tails, to perform a blood sugar test (ACCU-CHEK blood glucose meter; Roche Diagnostics, GmbH, Mannheim, Germany) and 24-h microalbuminuria test. The induction of 
diabetes was considered successful when blood sugar was $>16.17 \mathrm{mmol} / \mathrm{l}$. The same amount of sterile citrate buffer was injected intraperitoneally in mice of the control group. The mice were then fed with a high-fat diet for one month, and the blood sugar test and 24-h microalbuminuria test were repeated. The establishment of the mouse model of diabetic nephropathy was confirmed with the blood sugar as $>16.17 \mathrm{mmol} / \mathrm{l}$ and the quantification of 24-h urinary albumin increased to $>150 \%$.

Animal grouping and drug administration. Sixty-two animals were randomly divided into five groups: control (group A, n=12), model (group B, $n=12$ ), losartan (group C, $n=13$ ), low-dose Shen'an granules (group D, $n=13$ ) and high-dose Shen'an granules (group $\mathrm{E}, \mathrm{n}=13$ ). For drug administration, mice in the control and model groups were given $10 \mathrm{ml} /(\mathrm{kg} \cdot$ day $)$ distilled water by gavage, mice in the Western medicine group were administered $10 \mathrm{ml} /(\mathrm{kg} \cdot$ day) losartan suspension by gavage, and mice in the high- and low-dose Chinese medicine group were administered $4 \mathrm{ml} /(\mathrm{kg} \cdot$ day $)$ and $8 \mathrm{ml} /(\mathrm{kg} \cdot$ day $)$ Shen'an granules suspension, respectively. The mice were treated with drugs for 8 weeks.

Sample collection. Prior to and after drug treatments, the blood samples were collected from the retro-orbital plexus, and 24-h urine samples were collected for biochemical indices. After the drug treatment, kidneys without renal capsules were collected and weighed on an analytical balance. The left kidney was rapidly removed and a part of the renal cortex was cut into small sections and fixed in $4 \%$ paraformaldehyde for pathological examinations, while the right kidney was saved at $-70^{\circ} \mathrm{C}$ for subsequent use.

Biochemical tests. Coomassie Brilliant Blue assay (Guge Biological Technology Co., Hubei, China) was used for 24-h microalbuminuria. An AU600 Biochemistry Analyzer (Olympus Corp., Tokyo, Japan) was used to measure serum creatinine ( $\mathrm{SCr}$ ), blood urea nitrogen (BUN), triglycerides (TG) and total cholesterol (CHOL).

Western blot assay for Wntl and $\beta$-catenin protein. Total protein was extracted from a part of the renal cortex and the protein concentration was determined using a Bradford protein assay. SDS-acrylamide gel (Guge Biological Technology Co.) was created and separated proteins were transferred to a membrane. The membrane was blocked in 5\% skim milk at $24^{\circ} \mathrm{C}$ for $1 \mathrm{~h}$, incubated with primary polyclonal antibodies Wnt1 (Abcam, Cambridge, MA, USA, cat no.: ab15251; dilution, 1:5000) and $\beta$-catenin (Abcam, cat no.: ab32572; dilution, 1:5000) at $4^{\circ} \mathrm{C}$ overnight followed by three washes in TBST for $5 \mathrm{~min}$ each. The membrane was then incubated with the secondary polyclonal antibody (Abcam, cat. no.: ab6721; dilution, 1:2000 for $30 \mathrm{~min}$ at $24^{\circ} \mathrm{C}$, washed with TBST 3 times for 5 min each and protein bands were detected with DAB. The blot was scanned and optical density values of the targeted bands were analyzed with Alpha software (Chicago, IL, USA).

Reverse transcriptase-quantitative polymerase chain reaction (RT-qPCR). RT-qPCR was performed on paraffin-embedded mouse renal cortex sections. In detail, total RNA was extracted by RNA Isolation Kit (Biosharp, Hebei, China). Dnase I-treated
Table I. Primer sequences for RT-qPCR.

\begin{tabular}{ll}
\hline Gene & \multicolumn{1}{c}{ Primer sequences } \\
\hline$\beta$-catenin & F: 5'-AAAATGGCAGTGCGTTTAG 3' \\
& R: 5'-TTTGAAGGCAGTCTGTCGTA-3' \\
Wnt1 & F: 5'-CAGAGCCACGAGTTTGGATGTT-3' \\
& R: 5'-GATTGGGTTGGGTTGGAGGTAA-3' \\
$\beta$-actin & F: 5'-CCTGTACGCCAACACAGTGC-3' \\
& R: 5'-ATACTCCTGCTTGCTGATCC-3' \\
\hline
\end{tabular}

F, forward; R, reverse.

Table II. Measurements of 24-h urine albumin excretion prior to and after the drug treatment (mean $\pm \mathrm{SD})$.

\begin{tabular}{lccc}
\hline & & \multicolumn{2}{c}{$\begin{array}{c}\text { Measurements of 24-h urine } \\
\text { albumin excretion }(\mu \mathrm{g})\end{array}$} \\
\cline { 3 - 4 } Group & $\mathrm{n}$ & Before & After \\
\hline A & 12 & $26.46 \pm 8.45$ & $25.00 \pm 3.39$ \\
B & 10 & $272.80 \pm 70.45^{\mathrm{a}}$ & $312.00 \pm 8.37$ \\
C & 11 & $244.00 \pm 32.86^{\mathrm{a}}$ & $183.20 \pm 12.44^{\mathrm{b}}$ \\
D & 13 & $238.00 \pm 37.68^{\mathrm{a}}$ & $185.40 \pm 15.65^{\mathrm{b}}$ \\
E & 12 & $244.00 \pm 33.62^{\mathrm{a}}$ & $178.00 \pm 14.83^{\mathrm{b}}$ \\
\hline
\end{tabular}

Compared with the measurement in the ${ }^{\mathrm{a}}$ control group, $\mathrm{p}<0.05$; brior to the treatment in the same group, $\mathrm{p}<0.05$.

total RNA $(10 \mu \mathrm{g})$ was used for reverse transcription with Superscript III (Invitrogen, Carlsbad, CA, USA). Input RNA (100 ng) was amplified by RT-PCR using the TaqMan PCR reagent kit and assay-on-demand gene expression products. After reverse transcription, standard cDNA was serially diluted to five standard solutions to prepare the reference curve. RT-qPCR was carried out using the Rotor-Gene 3000 Real-Time PCR kit (Corbett Research, Sydney, Australia) with SYBR-Green (1:1,000; Molecular Probes, Houston, TX, USA). After reverse transcription, standard cDNA was serially diluted to five standard solutions to prepare the standard curve. The relative amount of cDNA in each sample was measured by interpolation using the standard curve, and the relative ratio of $\beta$-catenin and Wntl to $\beta$-actin expression was calculated for each sample. The primers are as shown in Table I.

Statistical analysis. Data were analyzed using SPSS 17.0 statistical software (Chicago, IL, USA) and presented as mean \pm standard deviation. Comparisons between groups were analyzed with ANOVA. $\mathrm{P}<0.05$ was considered to indicate a statistically significant difference.

\section{Results}

Shen'an granules treatment decreases urine albumin excretion. The urine albumin excretion of groups C-E was significantly 
Table III. Measurements of BUN and SCr values before and after the drug treatment (mean \pm SD).

\begin{tabular}{|c|c|c|c|c|c|}
\hline \multirow[b]{2}{*}{ Group } & \multirow[b]{2}{*}{$\mathrm{n}$} & \multicolumn{2}{|c|}{ BUN (mmol/l) } & \multicolumn{2}{|c|}{$\mathrm{SCr}(\mu \mathrm{mol} / 1)$} \\
\hline & & Before & After & Before & After \\
\hline A & 12 & $10.57 \pm 1.64$ & $12.80 \pm 0.84$ & $12.07 \pm 1.38$ & $14.20 \pm 1.48$ \\
\hline B & 12 & $24.56 \pm 1.89^{a}$ & $30.98 \pm 6.77$ & $45.41 \pm 7.31^{\mathrm{a}}$ & $52.80 \pm 3.96$ \\
\hline $\mathrm{C}$ & 12 & $20.86 \pm 2.76^{\mathrm{a}}$ & $15.78 \pm 0.90^{\mathrm{b}}$ & $48.20 \pm 2.86^{\mathrm{a}}$ & $26.20 \pm 1.10^{\mathrm{b}}$ \\
\hline $\mathrm{D}$ & 13 & $20.20 \pm 1.92^{\mathrm{a}}$ & $15.62 \pm 1.06^{\mathrm{b}}$ & $46.52 \pm 2.86^{\mathrm{a}}$ & $26.40 \pm 2.30^{\mathrm{b}}$ \\
\hline $\mathrm{E}$ & 13 & $19.78 \pm 1.81^{\mathrm{a}}$ & $13.80 \pm 1.30^{\mathrm{b}}$ & $44.80 \pm 2.39^{\mathrm{a}}$ & $22.80 \pm 1.79^{b}$ \\
\hline
\end{tabular}

${ }^{\mathrm{a}}$ Compared with the measurement in the control group, $\mathrm{p}<0.05 ;{ }^{\mathrm{b}}$ compared with the measurement prior to treatment in the same group, $\mathrm{p}<0.05$. BUN, blood urea nitrogen; $\mathrm{SCr}$, serum creatinine.

Table IV. Measurements of CHOL and TG values before and after the drug treatment (mean \pm SD).

\begin{tabular}{llcccc}
\hline & & \multicolumn{2}{c}{ CHOL $(\mathrm{mmol} / \mathrm{l})$} & \multicolumn{2}{c}{ TG $(\mathrm{mmol} / \mathrm{l})$} \\
\cline { 5 - 6 } Group & $\mathrm{n}$ & Before & After & Before \\
\hline A & 12 & $2.98 \pm 0.21$ & $2.88 \pm 0.03$ & $1.34 \pm 0.19$ & $1.42 \pm 0.12$ \\
B & 12 & $5.90 \pm 0.26^{\mathrm{a}}$ & $6.50 \pm 0.16$ & $3.38 \pm 0.09^{\mathrm{a}}$ & $4.50 \pm 0.17$ \\
C & 12 & $5.83 \pm 0.16^{\mathrm{a}}$ & $5.21 \pm 0.02^{\mathrm{b}}$ & $3.37 \pm 0.06^{\mathrm{a}}$ & $4.20 \pm 0.08^{\mathrm{b}}$ \\
D & 13 & $5.88 \pm 0.18^{\mathrm{a}}$ & $5.14 \pm 0.09^{\mathrm{b}}$ & $3.42 \pm 0.09^{\mathrm{a}}$ & $3.94 \pm 0.08^{\mathrm{b}}$ \\
E & 13 & $5.96 \pm 0.11^{\mathrm{a}}$ & $5.03 \pm 0.10^{\mathrm{b}}$ & $3.37 \pm 0.10^{\mathrm{a}}$ & $3.87 \pm 0.20^{\mathrm{b}}$ \\
\hline
\end{tabular}

${ }^{\mathrm{a}}$ Compared with the measurement in the control group, $\mathrm{p}<0.05$; ${ }^{\mathrm{b}}$ compared with the measurement prior to treatment in the same group, $\mathrm{p}<0.05$. CHOL, total cholesterol; TG, triglycerides.

lower compared to group B (model group) (Table II; $\mathrm{p}<0.05$ ). There were no significant differences between group $\mathrm{C}$ and the lower (group D) or higher (group E) Shen'an granules group $(p>0.05)$. The results suggested that the Shen'an granules treatment significantly decreased urine albumin excretion, effects that were equal to those of the losartan treatment (group C).

Shen'an granules treatment decreases the BUN and $\mathrm{SCr}$ level. Prior to the drug treatment, the levels of $\mathrm{BUN}$ and $\mathrm{SCr}$ in groups $\mathrm{C}-\mathrm{E}$ were significantly higher than those in group A (Table III; $\mathrm{p}<0.05$ ). However, no difference was found in groups B-E ( $p>0.05)$. The levels of BUN and $\mathrm{SCr}$ following the Shen'an granules treatment (groups D and E) were significantly lower compared with levels prior to the drug treatment (group B, p<0.05). Furthermore, the BUN and SCr levels were similar between the losartan treatment group (group B) and the Shen'an granules treatment group (Table III; $\mathrm{p}>0.05$ ).

Shen'an granules treatment increases TG level and decreases the CHOL level. To investigate the blood lipid levels in blood the TG and CHOL levels were also examined. The results showed that the Shen'an granules treatment (groups D and E) significantly increased the TG level compared to group B (model group) (Table IV; $\mathrm{p}<0.05)$. Furthermore, the Shen'an granules treatment also significantly decreased the CHOL level compared to group B. Notably, the effects of Shen'an granules could even achieve the level of losartan (Table IV).
Shen'an granules inhibits the Wntl and $\beta$-catenin protein expression. To investigate the mechanism of the effects of Shen'an granules treatment, the Wnt pathway molecule was detected. The western blot assay showed that Wnt1 protein expression in groups D and E was significantly decreased compared to group B (Fig. 1; p<0.05). Additionally, there was no significant differences between the Shen'an granules treatment group (groups D and E) and the losartan treatment group (group C) $(\mathrm{p}>0.05)$. There were also no significant differences between the lower (group D) and higher (group E) Shen'an granules treatment group $(\mathrm{p}>0.05)$.

The $\beta$-catenin protein expression was significantly decreased in groups D and E compared to group B (Fig. 1; $\mathrm{p}<0.05)$. There were no significant differences between groups D and E, and group C ( $>0.05)$. Furthermore, there were no significant differences between groups D and $\mathrm{E}$ $(\mathrm{p}>0.05)$.

Shen'an granules suppress Wntl and $\beta$-catenin protein expression. Wnt1 and $\beta$-catenin mRNA transcription were examined using the PCR assay. The results indicated that the Wnt 1 and $\beta$-catenin mRNA expression levels were significantly decreased in groups $\mathrm{D}$ and $\mathrm{E}$ compared to group B (Fig. 2; p<0.05). There were no significant differences between groups $\mathrm{D}$ and $\mathrm{E}$, and group $\mathrm{C}(\mathrm{p}>0.05)$. There were also no significant differences between groups D and $\mathrm{E}$ $(\mathrm{p}>0.05)$. 
A

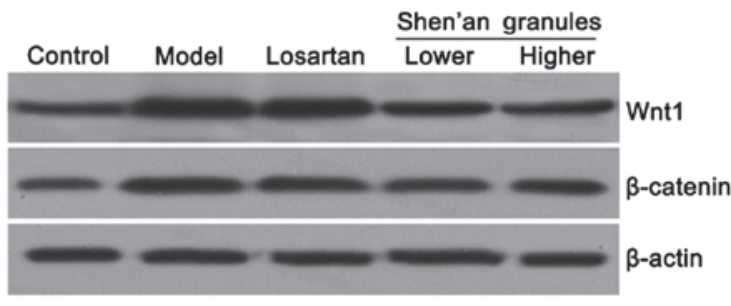

B

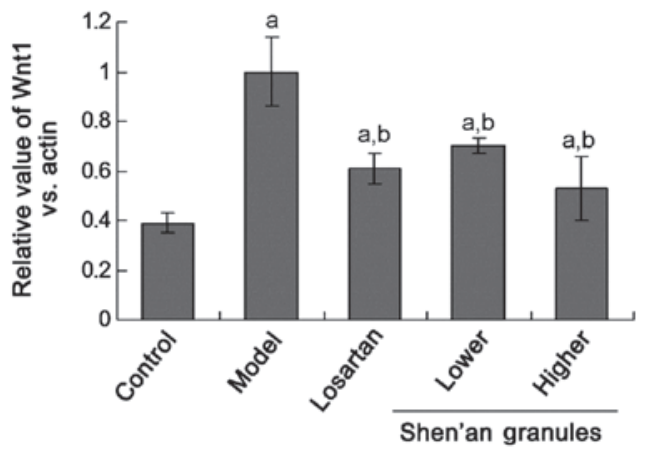

C



Figure 1. Wnt1 and $\beta$-catenin protein expression in mouse renal cortex. (A) Western blot assay showing decreased Wnt1 and $\beta$-catenin protein expression for groups D and E. Statistical analysis of (B) Wnt1 and (C) $\beta$-catenin protein expression. ${ }^{\mathrm{a}}$ Compared with the control group, $\mathrm{p}<0.05$; ${ }^{\mathrm{b}}$ compared with the model group, $\mathrm{p}<0.05$. Group A, control; group B, model; group C, losartan; group D, lower-dose Shen'an granules; group E, higher-dose Shen'an granules.

A

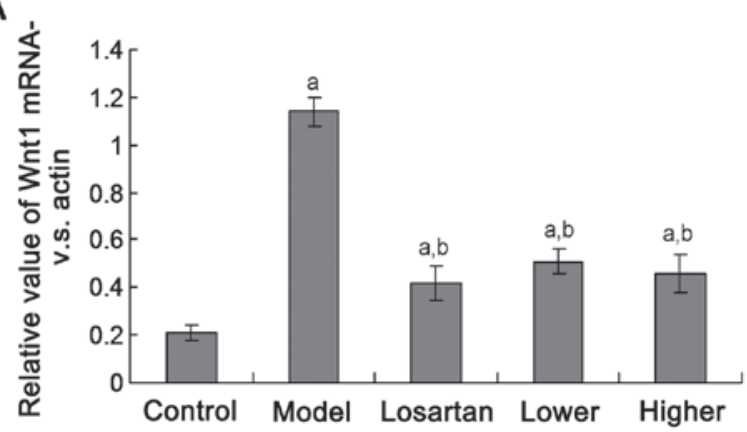

B

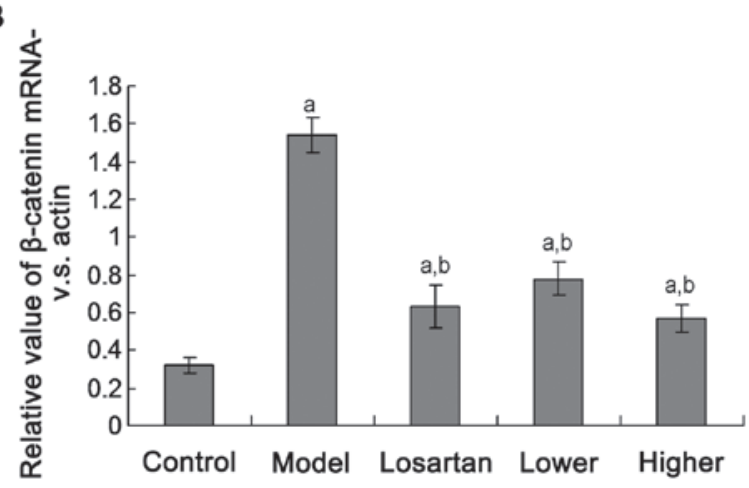

Figure 2. Examination of Wnt1 and $\beta$-catenin mRNA expression in mouse renal cortex. (A) Statistical analysis for Wnt1 mRNA expression by PCR assay. (B) Statistical analysis for $\beta$-catenin mRNA expression by PCR assay. ${ }^{\mathrm{a} C}$ Compared with the control group, $\mathrm{p}<0.05 ;{ }^{\mathrm{b}}$ compared with the model group, $\mathrm{p}<0.05$. Group A, control; group B, model; group C, losartan; group D, lower dose Shen'an granules; group E, higher dose Shen'an granules.

\section{Discussion}

Diabetic nephropathy is a glomerular sclerosis caused by the abnormal metabolism of diabetes mellitus, and constitutes an important component of systemic microangiopathy (4). In China, diabetic nephropathy is second only to glomerular disease as the leading cause of end-stage renal disease (ESRD), and constitutes an important cause for mortality in diabetes. Compared with non-diabetic nephropathy, renal insufficiency in diabetic nephropathy features higher proteinuria, and more severe edema. These features may be associated with podocyte injury and damage of the glomerular filtration barrier, leading to large amounts of protein leaking into urine, decreased body protein level and reduced plasma colloid osmotic pressure, which result in gradual aggravation of edema (5).

In diabetic nephropathy, the canonical Wnt signaling pathway is abnormally activated (6-8). In microdissected human kidney samples collected from patients with diabetic nephropathy, FSGS, and IgA nephropathy, microarray analysis has shown that the $\mathrm{Wnt} / \beta$-catenin pathway is a continuously upregulated pathway (9). The sustained activation of this pathway in podocytes leads to the development of proteinuria and glomerular sclerosis. Dai et al successfully induced the accumulation of $\beta$-catenin in podocytes by intravenous injection of a Wnt1-expressing plasmid in mice, and a transient proteinuria and podocyte foot process effacement occurred shortly after the stable expression of $\beta$-catenin (10). Kato et al found that at 20 weeks, the heterozygous mice (NPHS2cre/Ctnnb1FloxE3/WT) with a stable $\beta$-catenin expression in podocytes exhibited mild mesangial proliferation and proteinuria, as well as diffuse and irregular thickening of the glomerular basement membrane observed by electron microscopy (3). By contrast, the homozygous mice with stable $\beta$-catenin expression exhibited prominent thickening of the glomerular basement membrane and a large amount of proteinuria and glomerular sclerosis.

Previous findings showed that a sustained high expression of $\beta$-catenin causes podocyte epithelial-mesenchymal transition (EMT), increased expression of Snail, inhibition 
of E-cadherin, and a decreased expression of the podocyte marker nephrin in vitro and in vivo $(3,10,11)$. Mouse models and podocytes treated with a Wnt signaling pathway inhibitor exhibited improved cell survival, decreased cell-matrix adhesion, increased mobility, and reduced migration. In a previous study, mouse urine samples were tested and large numbers of shedded podocytes were found, supporting that the abnormal activation of Wnt/ $\beta$-catenin signaling pathway reduces podocyte adhesion, resulting in proteinuria and glomerular sclerosis (3). At the time, when the expression of podocyte marker nephrin is altered, the cells obtain the expression of mesenchymal cell markers, such as matrix metalloproteinase-7 (MMP-7), and the process of EMT leads to an increased mobility of podocytes and to a certain degree, damages the structural integrity of the filtration barrier, and eventually results in the leakage of large amounts of protein into urine (12). The mechanism may be associated with the interaction between $\beta$-catenin and integrin $\beta 1$, calmodulin-dependent protein kinase II, or angiotensin II (13). These phenotypes are similar to those exhibited in podocyte-specific Ilk, Ddrl, Itgbl and Itga3 gene-knockout animal models, suggesting that these genes may be components of the same signaling pathway $(14,15)$.

The basic pathogenesis of diabetic nephropathy is congenital insufficiency of kidney essence, and spleen-kidney dual deficiency. Dysfunction of kidney for the activation of Qi, hypofunction of ascending lucidity caused by spleen deficiency, and non-consolidation of essences lead to large amounts of proteins while other essences leak into urine (16). Spleen-kidney yang deficiency causes failure of moist evaporation and water transportation, internal stagnation and diffusion of fluid-dampness, which eventually result in edema. Long-term stagnation of fluid-dampness may produce phlegm and stasis, and the accumulation of phlegm turbid in turn further affects the ascending and descending of vital Qi, aggravating the leakage of protein and other essences (17). Shen'an granules are composed of astragalus, epimedium, and rhubarb at a ratio of 2:2:1. Although the formula only contains three ingredients, it is established through long-term clinical practice and has definite efficacy. In the formula, astragalus can strengthen the spleen and ascend the clear, which induce diuresis in order to alleviate edema; epimedium can warm kidney and protect semen, thus improving Qi transformation and inducing diuresis (18). The combination of the two herbs replenishes both inborn and acquired deficiency, and replenishes, and consolidates vital essences, leading to the recovery of the function of spleen and kidney on the regulation of fluid-dampness. Furthermore, the wine-processed rhubarb of only half the amount of astragalus and epimedium can eliminate side effects and maintain beneficial effects, resolve stasis and turbidity without damaging the vital Qi, and also clears the stasis and turbidity from excrement $(19,20)$. The combination of the three herbs can eliminate side effects and maintain beneficial effects, nourish the basics of spleen-kidney, recover their functions, consolidate the essences, remove stasis and turbidity, and replenish the vital essence, leading to the effective relief of symptoms, such as proteinuria and edema, in patients with diabetic nephropathy.

The results of the present study have shown that the expression levels of Wnt 1 and $\beta$-catenin proteins in the model group were significantly lower than those in the control group, and the expression was positively correlated with SCr, urea nitrogen, CHOL, and TG. Different concentrations of Shen'an granules can inhibit the expression of Wnt1 and $\beta$-catenin proteins, and decrease levels of 24-h urine albumin, SCr, BUN, CHOL, and TG, thereby reducing urinary protein, improving renal function, and regulating lipid metabolism. Experiments demonstrated that Shen'an granules reduce urinary protein, improve renal function, and regulate lipid metabolism by inhibiting the abnormal activation of the Wnt signal transduction pathway, thereby delaying the progression of diabetic nephropathy. The study provided experimental basis for Wnt signal transduction pathway as a new target for the treatment of diabetic nephropathy using Chinese traditional medicines.

\section{Acknowledgements}

The present study was granted by the Natural Science Foundation of Hubei Province (grant no. 2010CDA033).

\section{References}

1. Chen C, Lu Y, Liu J, Li L, Zhao N and Lin B: Genome-wide ChIP-seq analysis of TCF4 binding regions in colorectal cancer cells. Int J Clin Exp Med 7: 4253-4259, 2014.

2. Kawakami T, Ren S and Duffield JS: Wnt signalling in kidney diseases: dual roles in renal injury and repair. J Pathol 229: 221-231, 2013.

3. Kato H, Gruenwald A, Suh JH, Miner JH, Barisoni-Thomas L, Taketo MM, Faul C, Millar SE, Holzman LB and Susztak K: Wnt $/ \beta$-catenin pathway in podocytes integrates cell adhesion, differentiation, and survival. J Biol Chem 286: 26003-26015, 2011.

4. Auinger M, Edlinger R, Prischl F, Kautzky-Willer A, Prager R, Rosenkranz AR, Roden M, Saemann M, Clodi M and Schernthaner G: [Diabetic nephropathy - update 2012]. Wien Klin Wochenschr 124 Suppl 2: 42-49, 2012.

5. Dalla VM, Masiero A, Roiter AM, Saller A, Crepaldi G and Fioretto P: Is podocyte injury relevant in diabetic nephropathy? Studies in patients with type 2 diabetes. Diabetes 52: 1031-1035, 2003.

6. Zhou T, He X, Cheng R, Zhang B, Zhang RR, Chen Y, Takahashi Y, Murray AR, Lee K, Gao G, et al: Implication of dysregulation of the canonical wingless-type MMTV integration site (WNT) pathway in diabetic nephropathy. Diabetologia 55: 255-266, 2012.

7. He W, Dai C, Li Y, Zeng G, Monga SP and Liu Y: Wnt/ $\beta$-catenin signaling promotes renal interstitial fibrosis. J Am Soc Nephrol 20: 765-776, 2009.

8. He W, Kang YS, Dai C and Liu Y: Blockade of Wnt/ $\beta$-catenin signaling by paricalcitol ameliorates proteinuria and kidney injury. J Am Soc Nephrol 22: 90-103, 2011.

9. Woroniecka KI, Park AS, Mohtat D, Thomas DB, Pullman JM and Susztak K: Transcriptome analysis of human diabetic kidney disease. Diabetes 60: 2354-2369, 2011.

10. Dai C, Stolz DB, Kiss LP, Monga SP, Holzman LB and Liu Y: Wnt/beta-catenin signaling promotes podocyte dysfunction and albuminuria. J Am Soc Nephrol 20: 1997-2008, 2009.

11. Iglesias DM, Hueber PA, Chu L, Campbell R, Patenaude AM, Dziarmaga AJ, Quinlan J, Mohamed O, Dufort D and Goodyer PR: Canonical WNT signaling during kidney development. Am J Physiol Renal Physiol 293: F494-F500, 2007.

12. He W, Tan RJ, Li Y, Wang D, Nie J, Hou FF and Liu Y: Matrix metalloproteinase-7 as a surrogate marker predicts renal Wnt/ $\beta$-catenin activity in CKD. J Am Soc Nephrol 23: 294-304, 2012.

13. Jiang L, Xu L and Song Y: Li j,Mao J, Zhao AZ, He W, Yang J and Dai C: Calmodulin-dependent protein kinaseII/cAMP response element-binding protein/Wnt/beta-catenin signaling cascade regulates angiotensin II-induced podocyte injury and albuminuria. J Biol Chem 288: 23368-23379, 2013. 
14. Pozzi A, Jarad G, Moeckel GW, Coffa S, Zhang X, Gewin L, Eremina V, Hudson BG, Borza DB, Harris RC, et al: Beta1 integrin expression by podocytes is required to maintain glomerular structural integrity. Dev Biol 316: 288-301, 2008.

15. Jin Y, Wang L, Duan Q, Gong Z, Yang F and Song Y: Differential expression of 5-HT-related genes in symptomatic pulmonary embolism patients. Int J Clin Exp Med 8: 512-518, 2015.

16. Lv J, Wang YX and Liu YN: Exploration of heat treatment for diabetic nephropathy from the inflammation pathogenesis. Chin J Integr Trad Western Nephrol 15: 60-61, 2014 (In Chinese).

17. Wang YH, Pan Z and Wang YX: Molecular pathological basis ofabdominal mass in Shen collaterals. J Beijing Univ Trad Chin Med 29: 301-303, 2006 (In Chinese).
18. Chen LJ, Wang XQ and Ping AY: Influence of kidney-qi-nourishing therapy on T lymphocyte subgroup of spleen in natural abortion model mice. Chin Archives Trad Chin Med: 2012

19. Qian H, Yang JJ, Pan DY, Tang WT, Xu KJ and Qi MY: [Protective effectof total flavonoids of epimedium on the kidney in experimental diabetic rats]. Zhongguo Ying Yong Sheng Li Xue Za Zhi 30: 314-317, 2014 (In Chinese).

20. Ye D, Wu Z, Zhang T and Yue Y: Experimental study of rhubarb and epimedium decoction in counteracting hearing impairment due to chronic renal failure. Acta Univ Trad Med Sin Pharmacol Shanghai: 1998. 